solution. I found it exciting to read of his groping in the dark, methodically testing all conceivable intermediates until he discovered that "one molecule of ornithine could bring about the formation of more than twenty molecules of urea, provided that ammonia was present". From that moment the tracing of the other intermediates followed logical steps. It was the first biological process in which the intermediates were found to play a purely catalytic role. Krebs made this fundamental discovery while in charge of a medical ward with over 40 beds, which makes his feat even more remarkable.

Krebs's unravelling of the citric acid cycle in 1937 was to win him even greater fame, but his letter to Nature announcing it was rejected by the editor, Sir Richard Gregory, who at that time took it upon himself to judge the scientific worth of most of the communications sent to him. (It is not known whether Krebs's paper was refereed, but that seems unlikely Ed.)

Objections were raised at first against both the cycles. Those against the ornithine cycle were later found to be based either on wrong experiments or incorrect interpretation, while those against the precise chemistry of the citric acid cycle seemed fundamental. Biochemists argued that radioactively labelled $\mathrm{CO}_{2}$ introduced into the cycle should become randomly distributed among the two carboxyl groups of $\alpha$-ketoglutaric acid, an intermediate two steps after citric acid, because an enzyme would not be able to distinguish between the two symmetry-related carboxyl groups of citric acid. In fact, only the carboxyl nearest to the keto group of $\alpha$-ketoglutaric acid was found to be labelled; hence, it was concluded, citric acid could not be an intermediate in the Krebs cycle. That was in 1941 . I would have been desperate if an apparently valid objection had been made to my most fundamental discovery in which I could detect no flaw, but Krebs writes as though it had never cost him any sleep. Was he really so placid that he did not continuously turn over in his mind all conceivable explanations of the paradox, or did the sunshine of his later glory dissolve the memory of the seven clouded years that were to elapse before A. Ogston, in a brief and classic note to Nature, pointed out the fallacy in the objection: a symmetric molecule attaching itself to an enzyme at three points may give rise to only one of two possible asymmetrical reaction products. This was the birth of the concept of prochirality.

The glory was first heralded in October 1952 by eager journalists who told Krebs that he would shortly be awarded the Nobel Prize, but the rumours proved false and S.W. Waksman received it instead. Krebs relates proudly that the rumours left him and his wife unruffled. But did they really? Nine years later similar rumours about John Kendrew and me were floating

\title{
Scherzo metabolico cantabile
}

\author{
Thomas A. Scott
}

The Biochemists' Songbook. By Harold Baum. Pp.62. Pbk ISBN 0-08-027370-X. (Pergamon: 1982.) £2.45, \$4.95.

How refreshing, in the $1980 \mathrm{~s}$, to find a professor of biochemistry writing, not a solemn research text, but humorous biochemical verses. Thirteen important topics of biochemistry have been rendered by Professor Baum into light-hearted songs and set to appropriate popular tunes with piano accompaniment. The biochemical accuracy of the outrageous doggerel can be checked at a glance, because each song appears with the conventional scheme or account.

According to the author, all the songs were written while travelling on the top deck of a No. 22 bus; this I do not believe. He also points out that they are intended for communal singing, ideally with a blood alcohol level of $35 \mathrm{mg}$ per cent; this I do believe. Some of the scansions are tortuous and not always immediately obvious. While the alcohol will not make them any easier, it will stop you worrying whether you get them right.

Perhaps the greatest challenge is in the first verse of "Protein Biosynthesis":

Introns and exons, changes post-transcriptional, and all Glycosylations, don't alter such basics at all

to the tune of My Bonny Lies Over the Ocean. In contrast other compositions have a reassuring and earthy quality, for instance:

If you gobble tagliatelli,

Chicken soup with vermicelli,

You'll acquire a sagging belly -

are the opening lines of "Fatty Acid Biosynthesis" set to Men of Harlech.

Surprisingly, the author has failed to exploit the rousing coda of Macnamara's Band in "The Pentose Phosphate Shunt". Admittedly, this loud and rasping interlude is normally left to the trombones, but it is tailor-made for Professor Baum's particular style of ethanolic chorus; in the second edition perhaps? Also, these days, when so many bar pianists are over forty, and all the young wags play the guitar, this already excellent songbook might be made more usable by the younger generation by the inclusion of harmony frets or chord names for each tune.

The Biochemists' Songbook is dedicated jointly to Sir Hans Krebs on his eightieth birthday and to the author's wife. Sir Hans has also contributed a foreword, and there is a certain poignancy in the publication of the Songbook so shortly after his death. His cycle is set to Waltzing Matilda, and this year the International Congress of Biochemistry will be held in Australia, where it is no novelty, indeed it is a long established tradition, to sing this tune communally and with a blood alcohol level rather in excess of that recommended by Professor Baum.

Thomas Scott is Senior Lecturer in Biochemistry at Leeds University.

around our laboratory. We doubted them until my secretary rushed in, flourishing two telegrams, one addressed to Kendrew and the other to me. This was it. When we had eagerly torn them open we found them to be from the Pontifical Academy in Rome, enquiring how many reprints we wanted of the papers we had read there the previous autumn. We also pretended to a stoic calm. Unruffled or not, Krebs did receive the Prize the following year.

After nearly 20 happy years and the founding of a flourishing school of biochemistry at Sheffield, Krebs became
Professor of Biochemistry at Oxford and stayed there until his death last November. I was surprised by his statement that Oxford had remained in the forefront of learning for 600 years. Had he never read Edward Gibbons's description of its decline into sloth in the eighteenth century when dons could not even be bothered to teach their students? The picture of Oxford University in Krebs's own time conjured up in the book is of a citadel of unjust privileges jealously guarded by the Party members. Krebs got himself elected to the Central Committee by the under- 